\title{
Cinema nacional, para quem? Associações, recepção e transnacionalismo ${ }^{1}$
}

\author{
Cine nacional, para quién? Asociaciones, recepción y transnacionalismo \\ National cinema, for whom? Associations, reception, and transnationalism
}

Wolfgang Fuhrmann ${ }^{*}$

\section{Resumo}

Discursos sobre cinema nacional, normalmente, se focam no aspecto da produção e excluem as questões de distribuição e recepção. A partir de uma perspectiva transnacional, neste artigo procura-se analisar o papel das exibições de filmes provenientes de associações educativas alemãs no Brasil, nos anos 1930. A Associação de Professores Alemães em São Paulo, o Serviço Teuto-Brasileiro de Filmes Culturais e o Serviço de Filmes da Associação Nacional de Professores Teuto-Brasileiros mostraram filmes de não ficção de tipo cultural (Kulturfilme) da Alemanha para imigrantes alemães e brasileiros. No artigo, argumenta-se que a recepção das exibições deve ser interpretada não apenas em relação à propaganda fascista alemã, mas também no contexto de uma cultura cinematográfica nacional dinâmica.

Palavras-chave: Historiografia do cinema. Recepção. Transnacionalismo.

\section{Introdução}

Quando se tenta descrever e analisar acontecimentos históricos filmográficos de forma abrangente, pode-se chegar, muitas vezes, aos limites do método. Histórias nacionais do cinema focam com frequência as produções dos filmes locais e deixam de lado a questão da recepção e do público. $\mathrm{O}$ problema apresenta-se complexo quando, entre a exibição de filmes nacionais, encontram-se filmes estrangeiros destinados, por exemplo, a imigrantes em terreno nacional. Um dos principais argumentos do discurso do cinema nacional é a defesa da própria cultura e o perigo de um imperialismo cultural instigado (ou incentivado, ou sugeri-

Doutor em Letras pela Utrecht University, Holanda. Professor da University of Zurich, Suíça.

Recebido em 01/04/2016 - Aprovado em 01/09/2016 http://dx.doi.org/10.5335/hdtv.16n.2.6921 
do) por filmes e culturas estrangeiros (JARVIE, 2000, p. 78; HIGSON, 2000, p. 69). Neste artigo pretende-se demonstrar que, na área do cinema, se quisermos fazer justiça ao cruzamento das histórias filmográficas alemã e brasileira, tornar-se necessário uma descrição muito mais diferenciada da exibição e recepção de filmes de não ficção.

Deslocando-se o foco da história da produção do cinema para a história de sua distribuição e recepção, emergem novos conhecimentos históricos, que, geralmente, não surgiriam em uma historiografia do cinema nacional. Abordamos, portanto, a história da exibição de filmes pela Associação de Professores Alemães em São Paulo, (Deutscher Lehrerverein), pelo Serviço Teuto-Brasileiro de Filmes Culturais (Deutschbrasilianischer Kulturfilmdienst, D.K.D.), de São Leopoldo, e pelo seu sucessor, o Serviço de Filmes da Associação Nacional de Professores Teuto-Brasileiros (Filmdienst des Landesverbandes Deutsch-Brasilianischer Lehrer, L.D.L.). Todos esses órgãos foram, sobretudo nos estados do sul do Brasil, importantes para a divulgação do cinema alemão entre o período de 1931 e 1938 e permitem problematizar a esfera pública do cinema nacional e a recepção histórica de filmes de não ficção no Brasil a partir de uma perspectiva transnacional.

\section{Associações e cinema}

Filmes de não ficção não eram somente exibidos nos cinemas públicos. Existiam outros lugares de apresentação, onde o público assistia regularmente, ou irregularmente, a filmes de não ficção, por exemplo, em associações. Ao lado dos cinemas públicos, as associações cumpriram um papel importante na divulgação de filmes de não ficção e por essa razão elas também fazem parte da esfera pública, embora, muitas vezes, sejam negligenciadas pela historiografia do cinema. Focando-se na exibição de filmes fora do circuito de cinema, como os exibidos nos espaços representados pela grande rede das associações, mostra-se que muitas dessas associações usaram esse novo dispositivo para alcançar diferentes objetivos (FUHRMANN, 2015).

Em uma abordagem revisionista de Jürgen Habermas do conceito de esfera pública como domínio da vida social na qual o acesso é garantido a todos os cidadãos, estudiosos, como Nancy Fraser e Geoff Eley, argumentaram que, apesar de toda a retórica da abertura e da acessibilidade, sobre a qual a esfera pública oficial repousa, de fato, ela está constituída por um número significativo de exclusões (FRASER, 1992, p. 113). A abordagem dos revisionistas reconhece a existência de esferas públicas concorrentes em cada fase da história (ELEY, 1992, p. 306) e salienta a heterogeneidade dessas esferas como uma arena de contínuo conflito. Por isso, de acordo com Eley, faz mais sentido entender a esfera pública como "the structured setting where cultural and ideological contest and negotiation among a variety of publics takes place $[\ldots]^{\prime \prime}$.

A importância das associações na história alemã é enfatizada tanto por Thomas Nipperdey (1976, p. 175-205) como por Roger Chickering, que veem a proliferação de associações voluntárias como "um dos mais notáveis fenômenos culturais da época Wilhelmine" (CHICKERING, 1984, p. 183). No âmbito da nossa pesquisa, uma compreen- 
são mais matizada do caráter excludente bem como da diversidade da esfera pública pode ser fornecida pelo estudo da rede de associações voluntárias e da vida associativa, conforme Eley (1990, p. 291).

Um dos mais importantes recursos das associações foi o fato de elas terem se adaptado à dinâmica dos modernos processos sociais (NIPPERDEY, 1976, p. 182). A fé no progresso e nas transformações do mundo fez das associações um instrumento para a modernização da sociedade. A crescente complexidade da vida moderna foi também refletida pela variedade de atividades associativas. A maioria das associações era movida por objetivos não políticos, como entretenimento, autoformação e articulação de uma política de bem-estar comum.

A filiação a uma associação tem grande significado na vida cotidiana alemã, o que se estende nos países com imigração alemã. Imigrantes alemães levaram o idioma, os costumes e as tradições à nova terra natal e instalaram uma infraestrutura para praticar e preservar a cultura em clubes esportivos, orfeões, associações de beneficência, escolas, câmaras de comércio ou associações religiosas (MÜLLER, 1997, p. 150). Exibir filmes constituiu uma forma de preservar as tradições e a cultura, ligar a nova terra natal ao país de origem. Porém, para analisar a recepção desses filmes no Brasil é necessário uma outra abordagem, que considera a situação particular no contexto do cinema nacional brasileiro.

\section{Cinema e transnacionalismo}

O cinema sempre foi, e continua sendo, um meio de comunicação internacional, que, principalmente, nos contextos de distribuição e recepção tem peso transnacional. No seu artigo The limiting imagination of national cinema (HIGSON, 2000) o autor submete seu texto canônico, The concept of national cinema (HIGSON, 1989) a uma nova reflexão crítica. Considerando o conceito de Benedict Anderson sobre uma comunidade imaginada, imagined community (ANDERSON, 1991), Higson questiona a utilidade do conceito de cinema nacional que, ao lado de sua função rotuladora auxiliar, é ao mesmo tempo tautológico e fetichista (HIGSON, 2000, p. 64). Análises sobre o cinema nacional podem levar à limitação de filmes que mostram o país como um espaço fechado, no qual se encontra uma comunidade homogênea, que é fechada a qualquer outra identidade. $\mathrm{O}$ conceito de um cinema nacional não abarca a diversidade cultural, a troca e a permuta que caracterizam a atividade filmográfica. Fronteiras não são só meios de demarcação estatal, mas também passagens que possibilitam a migração e a troca (HIGSON, 2000, p. 67). No momento da ultrapassagem da fronteira nasce o conceito de transnacional, que parece ser muito mais adequado para descrever formações culturais e econômicas, porque elas não podem ser pensadas em termos de limitações nacionais. Fenômenos transnacionais afetam todas as áreas da cinematografia, seja em relação a coproduções ou a cineastas migrantes no nível da produção, seja em relação a questões da censura, da sincronização das legendas e do marketing ou em relação à 
recepção dos filmes nos contextos culturais específicos nos quais são vistos.

\section{Exibições de filmes pelas associações educativas}

Uma forma especial de filme didático cultural (Kulturfilm), típico do cinema alemão, foi especialmente fomentada nas áreas rurais de língua alemã a partir do final dos anos 1920. A visita de Edgar Beyfuss ao Brasil, em agosto de 1925, relata como foi esse começo. Naquela época, Beyfuss era dramaturgo da seção de filmes culturais da Universum Film A.G. (UFA) e provavelmente encontrava-se em turnê de propaganda para promover filmes culturais no Brasil. ${ }^{2} \mathrm{~A}$ palestra de Beyfuss na Escola Olinda, em São Paulo, a maior escola alemã da cidade, tinha o objetivo de esclarecer o público sobre o filme cultural alemão e, com a apresentação de um filme, proporcionar uma mirada por trás dos bastidores. ${ }^{3}$ Nos anos seguintes, as escolas alemãs - encabeçadas pela Escola Olinda - reforçaram as atividades cinéfilas, que foram influenciadas de forma decisiva pelas mudanças políticas na Alemanha e por uma rede cinematográfica privada no Brasil.

Antes da tomada do poder por Hitler, a Associação de Professores Alemães em São Paulo adquirira, em 1931, um projetor de filmes modelo Zeis-Ikon para aumentar o número de exibições na cidade e nas redondezas. ${ }^{4}$ A compra do projetor foi necessária depois que a associação recebeu dois filmes da Deutscher Bildspielbund, uma organização central na Alemanha, que se dedicava à coordenação da educação visual nas escolas alemãs e em instituições educativas. Outros três filmes, $\mathrm{Oh}$, du mein Vaterland (Oh, você minha pátria); Frohe Menschen (Pessoas felizes) ${ }^{5}$ e um sobre um evento desportivo em Colônia, em 1928, foram doados à Associação Nacional de Professores Teuto-Brasileiros. ${ }^{6}$

Em maio de 1931, a associação passou as primeiras informações sobre as mostras. Eles começaram as exibições em Presidente Venceslau, durante as festividades da Páscoa (5 a 8 de abril), seguidas por Campinas (25 de abril), na cidade de São Paulo, na Escola Olinda ${ }^{7}$ e Vila Marianna ${ }^{8}$ (2 de maio), e na Sala do Clube Alemão de Ginástica de 1890 (Deutscher Turnerschaft von 1890), em São Paulo (7 de maio), em Monte Mor (9 de maio), Cosmópolis (4 de junho) e em São Caetano (12 de junho). Todas as mostras foram bem-sucedidas, com as salas sempre repletas de público. Excluindo os gastos, a renda dos ingressos ficou para as escolas locais ou constituíram fonte importante para melhorar a situação financeira, como em Presidente Venceslau ou em São Caetano. ${ }^{9}$

Diante da precária distribuição de energia elétrica, as exibições de filmes em áreas rurais geralmente exigiam grande capacidade inventiva dos organizadores. Ao contrário das exibições nas cidades, na zona rural, muitas vezes, essas foram praticamente as primeiras exibições de filmes para a população local. ${ }^{10}$ Em Presidente Venceslau, o dínamo de uma carpintaria foi instalado em um caminhão para produzir eletricidade. Outras mostras foram transferidas para os cinemas públicos, por falta de energia, e uma mostra na colônia Friedburg (hoje Friburgo, um bairro da cidade de Campinas) teve de ser cancelada por falta de energia elétrica no local, um problema que só foi resolvido em $1935 .{ }^{11}$ 
Nos anos seguintes, a associação continuou suas exibições com muito sucesso e os filmes eram fornecidos pelo Bilderdienst. Entre eles, encontramos títulos como: Ein Besuch bei Hindenburg (Uma visita a Hindenburg), Das arbeitende Hamburg (Hamburg trabalhadora), Das schöne Hamburg (A linda Hamburgo), Die lüneburger Heide (Os pântanos de Luneburgo) e Ein Turnfilm (Um filme de ginástica). ${ }^{12}$

A notícia do trabalho e do sucesso da Associação de São Paulo chamou a atenção dos outros estados. Em junho de 1932, o Jornal dos professores, publicação da Associação Católica de Professores do Rio Grande de Sul (Lehrerzeitung: Vereinsblatt des Katholischen Lehrervereins in Rio Grande do Sul) publicou um artigo sobre a assembleia anual da Associação Paulista, incluindo as exibições dos filmes no estado. ${ }^{13}$ Com a referência dessa notícia, o professor Dr. Walter Kosche, do Instituto Pré-Teológico em São Leopoldo, Rio Grande do Sul ${ }^{14}$, contatou seus colegas em São Paulo e ofereceu uma parceria entre seu serviço de filmes culturais e o serviço paulista. ${ }^{15}$

Kosche mostrou experiência com a exibição de filmes. Interessado na cinematografia, desde abril de 1932 operava o Serviço Teuto-Brasileiro de Filmes Culturais (D.K.D.). A organização do D.K.D. era diferente daquela da associação de São Paulo. Da central em São Leopoldo, Kosche estabeleceu uma rede de agências de filmes que ficava aberta a todos que queriam ser sócios. Para entrar na rede, novos membros pagavam uma taxa que financiava a compra de novos filmes, projetores e o trabalho administrativo. O plano do serviço de filmes do D.K.D. baseou-se na constante circulação e troca de filmes entre as agências. ${ }^{16}$
A expansão do D.K.D. no ano 1933 foi o resultado da grande atividade pessoal de Kosche, que viajou extensivamente pelo estado, contatou por escrito com colegas, clubes e outras associações, para oferecer filmes de qualidade aos membros, que também solicitavam informações sobre o D.K.D. A correspondência com colegas não só permitiu Kosche informar sobre as obrigações e direitos dos membros, mas também sobre a disponibilidade de novos filmes. Em sua correspondência com a Associação de São Paulo, Kosche pediu informação sobre filmes como Berg des Schicksals (Monte do destino), um filme de Arnold Fanck de 1923/1924, Tertianerstreiche (Trotes de terceiro grau) ou "qualquer outro filme." ${ }^{17}$ A rica troca de correspondência permitiu igualmente a permuta de filmes entre as associações. $\mathrm{O}$ senhor Dr. Gustav Holl, de Bom Jesus, ofereceu a Kosche diversos filmes, entre eles o filme que ele estava procurando: Der Berg des Schicksals. Assim como Kakteen - und Orchideenblüten (Cactos - e flores orquídeas), São Lourenço und Umgebung, $120 \mathrm{~m}$ (São Lourenço e os arredores), Rosario-Prozession und Navegantesfest, $850 \mathrm{~m}$ (Procissão do Rosário e Festa dos Navegantes), Spiessbraten, $40 \mathrm{~m}$ (Churrasco) e quatro filmes de $30 \mathrm{~m}$ de Charles Chaplin e Jacky Coogan. ${ }^{18}$ O D.K.D. ofereceu exclusivamente filmes de formato reduzido que permitiam realizar sessões mais rápidas e econômicas. Quando o D.K.D. recebeu a oferta de distribuir filmes de formato normal, o serviço organizou mostras nas salas públicas de cinema.

A colaboração entre o D.K.D. e a Associação São Paulo somente aconteceu a partir de 27 de março de 1934, depois de um 
acordo feito em uma assembleia realizada durante os festejos do Schultag, em Blumenau, que aconteceram entre 27 de setembro e $1^{\circ}$ de outubro $1933 .{ }^{19}$ Com a colaboração, partir de 1934, o serviço passou a ser administrado pela Associação Nacional dos Professores Teuto-Brasileiros (L.D.L.). Em 1935, o serviço foi reestruturado e passou a se chamar Serviço de Filmes da Associação Nacional dos Professores Teuto-Brasileiros, L.D.L. Filmdienst. A direção do serviço mudou de São Leopoldo para São Paulo, sob a direção do Dr. Karl Otto Müller. Para facilitar o trabalho administrativo de São Paulo, o Filmdienst instalou uma subdiretoria provincial em Porto Alegre para atender os estados do sul do Brasil. ${ }^{20}$ Posteriormente, o novo serviço ramificou-se por todo o país com repartições distritais e regionais, chegando até a Bahia, no Nordeste brasileiro. No Rio Grande de Sul, ${ }^{21}$ incluía as cidades de São Leopoldo, Santa Cruz, Cachoeira, Santa Maria, Santo Ângelo, Belo Centro, Buricá, Ijuhy, Neu Württemberg, Carasinho, Boa Vista de Erechim, Erechim, Marcelino Ramos, Porto Novo, Porto Felix, São Lourenço, Pelotas, Bagé. Em Santa Catarina, Blumenau, Joinville, Porto União, Florianópolis. No Paraná, Curytiba, Ponta Grossa, Rio Negro-Mafra. Em Minas Gerais, Burnier, e uma repartição no Rio de Janeiro. Duas agências voadoras operadas pelas associações dos professores evangélicos e católicos ajudaram a rede no Rio Grande do Sul, uma agência no Espírito Santo formou-se em 1936. ${ }^{22}$

Os programas eram compostos exclusivamente por filmes mudos e em formatos reduzidos, que eram apresentados gratuitamente ou cobrada somente uma taxa para cobrir os custos da exibição. As exibições dos filmes de formato normal foram realizadas pelo Partido Nazista (N.S.D.A.P.) e pela representação oficial da Companhia Ferroviária do Reich (Reichsbahn), no Rio de Janeiro. ${ }^{23}$

Assim como as exibições cinematográficas promovidas pela Associação de Professores em São Paulo, as mostras promovidas pelo D.K.D. e pelo L.D.L eram também muito populares. Para o período entre 1931 e 1938 é possível comprovar inúmeros pedidos de associações e clubes que planejavam exibições ou sugeriam novas aquisições. Segundo o relatório da Escola Olinda, no primeiro ano, o D.K.D. organizou 99 noites de apresentações de filmes, 31 delas no interior do estado (MÜLLER, 1934, p. 74-77). Até março, o número de exibições crescera até 121 , em 29 lugares diferentes. ${ }^{24}$ O D.K.D ou o L.D.L. tinham como objetivo a distribuição de filmes culturais no Brasil. Os filmes deveriam "ajudar a manter a nacionalidade enquanto ligação viva com a terra natal" e fortalecer o ensino público alemão no Brasil. ${ }^{25}$ Por outro lado, os filmes produzidos pelo D.K.D. deveriam informar na terra natal (Heimat) sobre a "nacionalidade alemã no Brasil" ${ }^{26}$

Uma recepção ambivalente:filmes culturais e a ideologia nazista

Na sua investigação de fotografias históricas, Olga Rodrigues Moraes von Simson aponta que havia uma ideologia nacional-socialista no serviço educativo realizado pelo D.K.D. e pelo L.D.L.:

O trabalho de divulgação de filmes educativos tinha como objetivo, de acordo com o programa de expansão da ideologia nacional socialista para as colônias germânicas espalhadas pelos cinco continentes, manter 
a tradição teuta entre os colonos disseminados por todos os continentes, relatar as conquistas políticas, sociais e educacionais obtidas pelo nazismo na terra mãe e divulgar a vida dos colonos teuto-brasileiros na Alemanha, por meio de filmes documentários rodados no Brasil, estabelecendo assim uma religação entre as populações emigradas e a pátria de origem (VON SIMSON, 2005, p. 27).

A partir de 1933, o serviço do L.D.L. não pôde esquivar-se da influência da Organização do Partido Nazista para o exterior (Auslandsorganisation der N.S.D.A.P.). Os grupos nazistas locais tentaram influenciar as associações teuto-brasileiras nos anos seguintes. Quando o fornecimento com filmes de formato reduzido tornou-se cada vez mais difícil, a partir de 1936, a Organização do Partido Nazista foi um importante parceiro para garantir a sobrevivência do L.D.L. ${ }^{27}$ Porém, limitar as mostras de filmes dentro do contexto da ideologia nazista significava reduzir o conteúdo para a recepção do público histórico, o que caracteriza um aspecto ambivalente em termos de leitura dessa recepção.

É preciso perguntar-se sobre a relação entre os alemães que viveram no Brasil e ingressaram no Partido Nazista e os teuto-brasileiros que se opuseram à hegemonia nazista nos país. A maioria dos teuto-brasileiros cuidaram do idioma, da arte e da tradição da Alemanha, mas mostraram pouco interesse pela ideologia nazista (NAZARIO, 2007). Existiam vozes no Brasil que criticaram as ações do partido como sendo insensíveis e que corriam o risco de ameaçar a reputação dos teuto-brasileiros como "bons cidadãos brasileiros" (MÜLLER, 1997, p. 296). O número dos filiados ao N.S.D.A.P. fora da Ale- manha nunca foi significante, somente cinco por cento dos alemães entraram no partido (MÜLLER, 1997, p. 47). Dos 90 mil alemães radicados no Brasil que viviam no pais com cidadania alemã, Reichsdeutsche, o número de filiados ao Partido Nazista foi de 2.822, portanto 3,2\% (DIETRICH, 2007, p. 159). René Gertz lembra que

[...] entre os que ingressaram no partido provavelmente se encontrava um número significativo que estava numa dependência econômica direta em relação às empresas alemãs (da Alemanha) em atividade no Brasil, para as quais a adesão ao partido era quase uma obrigatoriedade (GERTZ, 1996, não paginado).

A grande maioria dos alemães no Brasil era de origem alemã, embora com cidadania brasileira, Volksdeutsche (alemães étnicos), e se consideravam teuto-brasileiros (DIETRICH, 2007, p. 157). Apesar dos sacrifícios impostos pelo Contrato de Versalhes, que os alemães sentiam como uma humilhação nacional, muitos teuto-brasileiros acreditavam em uma nação alemã nova e forte após o fim da guerra. Porém, o nacionalismo desse grupo não significava necessariamente ser um nacional-socialista, tampouco a subordinação ao Partido Nacional-Socialista (MÜLLER, 1997, p. 203-205).

Há uma dificuldade em avaliar a posição política, por exemplo, do alemão Kosche, de São Leopoldo. Apesar de ele citar, em uma correspondência de abril 1933, o livro Minha luta, de Hitler, que teria lido apenas para poder "tomar parte numa conversa", não podemos afirmar que estivesse de acordo com a ideologia nazista. O livro é citado vagamente em meio a outros assuntos de ordem cotidia- 
na. Suas correspondências tratam preponderantemente sobre cinema, mesmo que por vezes as assine com Filmheil, ${ }^{28}$ que poderia ser uma paródia da saudação nazista.

A ambivalência também caracteriza os filmes e os programas dos filmes. Um exemplo pode ser analisado com o filme mais popular de 1934, Der Tag von Potsdam (O dia de Potsdam). O filme mostra as festividades do encontro entre Adolf Hitler e o então presidente da Alemanha Paul von Hindenburg, duas semanas depois da eleição de Hitler como chanceler. ${ }^{29} \mathrm{O}$ filme pode ser entendido como uma glorificação a Adolf Hitler, mas também como um encontro entre o passado e o futuro da Alemanha, em que Hindenburg pode ser visto como um representante da Alemanha Imperial, com a qual muitos teuto-brasileiros também se identificavam. Além disso, as paisagens nostálgicas de Potsdam poderiam interessar ao público. Conservadorismo, germanismo e o cuidado com as tradições e costumes existiam antes da ideologia nazista, embora tenham sido por elas ressaltados. Porém, a ideologia nazista é "uma conglomeração de vários elementos ideológicos" (LUTHER, 2004, p. 59), que além de germanismo e tradição, inclui racismo, antissemitismo ou o culto a um líder.

\section{0 público dos filmes culturais}

Os filmes exibidos pelo D.K.D. ou pelo L.D.L. eram heterogêneos, assim como seu público. A programação dos filmes mostram uma convergência de propaganda cultural e dos objetivos do Partido Nazista. Além disso, é preciso considerar que existia um público brasileiro que também estava pre- sente durante as exibições. Analisando-se os filmes exibidos pelas associações e serviços entre 1931 e 1935/1936, nota-se que a exibição de filmes no Brasil resultou de um esforço da Associação de Professores no Exterior (Verein Deutscher Lehrer im Ausland, V.D.A.) da Alemanha, em 1930. Em janeiro, o jornal Die Deutsche Schule im Auslande, o órgão oficial dessa associação, lançou um primeiro artigo sobre propaganda cultural nas escolas exteriores (SCHMIDT, 1930).

Segundo o autor, a primeira guerra tinha acabado, porém novas lutas continuaram. Afora a luta econômica sobre matérias-primas e novos mercados, havia a luta cultural, que merecia a mesma atenção. Além da Ásia, da Europa e do Oriente, a América do Sul foi o quarto "campo de batalha" (SCHMIDT, 1930, p. 3) por uma propaganda cultural - uma política cultural alemã que não ameaçasse a cultura local. O autor acentua que o conhecimento da cultura alemã não tinha o objetivo de afastar estudantes que não eram alemães da própria cultura, mas usar a educação alemã como um "reforçador" entre as culturas (SCHMIDT, 1930, p. 9).

Em outro artigo, lê-se que a exibição de filmes culturais fez parte da propaganda cultural. A Companhia Ferrovia do Reich forneceu à V.D.A. um filme de $1.500 \mathrm{~m}$ sobre a Alemanha para ser exibido em todas as escolas e associações nas América do Sul e Central (PRINZHORN 1930, p. 405). Junto com textos explicativos em espanhol e português, o filme não era somente destinado a imigrantes de origem alemã, mas também a alunos e parentes que não eram alemães, que deveriam ver o filme durante um espectáculo social com música. O objetivo do 
filme, que "realmente é um filme de propaganda" (PRINZHORN, 1930, p. 405), como a associação notou, não era simplesmente mostrar a Alemanha, mas colocar o país como um concorrente da França, que ainda atraía a maioria de turistas da América do Sul. A primeira estreia do filme propaganda deveria ser no Brasil.

A heterogeneidade do público e a programação dificultam mais uma vez a análise da recepção. Filmes que foram apresentados nas áreas de imigração alemã e em escolas alemãs durante os anos das atividades do D.K.D. e L.D.L. não se originavam somente da Alemanha e não relatavam exclusivamente sobre ela. Seguindo-se os relatos e correspondências sobre eventos cinematográficos nas cidades e nas regiões rurais, o público também não era exclusivamente formado por alemães ou descendentes deles. O modelo mais plausível para entender a heterogeneidade da recepção dos filmes parece ser o conceito de encoding/ decoding de Stuart Hall: os filmes do serviço oferecem uma posição de leitura negociável ou mesmo uma oposição (HALL, 1999). ${ }^{30}$

Alemães compunham a menor parte dos alunos da Escola Olinda, que era frequentada em sua maioria por teuto-brasileiros, com um quarto do público composto por brasileiros e de outras nacionalidades. ${ }^{31}$ A exibição na escola do filme Brasil grandioso, em setembro de 1931, não se dirigiu exclusivamente a um público alemão. ${ }^{32}$

Nas regiões rurais, era praticamente impossível realizar apresentações cinematográficas sem a população de língua portuguesa. Como a propaganda cultural se dirigiu ao público no Brasil, como recomendada em 1930, podemos verificar em um letreiro no Cine Casari, em Presidente Venceslau:

"Hoje grandioso sucesso. UFA apresenta 2 Interessantes Filmes De Grande Cultura". $1^{\circ}$ Parte: Sport Em Geral Em 2 Bellas Partes; $2^{\circ}$ Parte, Minha Pátria Em 8 Partes Demonstrando As Mais Lindas Paisagens Da Alemanha (SOARES, 2009, p. 90).

A combinação de um filme desportivo e o título Minha pátria, muito parecido com $\mathrm{Oh}, \mathrm{du}$ mein Heimatland, sugere que a foto provavelmente foi tomada durante a turnê da Associação São Paulo, no dia 8 de abril 1931. Bruno Pinto Soares aponta o contradição do texto no letreiro:

Minha Pátria propõe-se a mostrar as mais belas paisagens da Alemanha, e o próprio nome convida a imaginar tratar-se de produção com teor nacionalista. O interessante, nessa questão, é a intenção em passar a película na área urbana da cidade, afinal a esmagadora maioria da comunidade teuta morava na área rural. Percebe-se que o filme não se endereçava ao público germânico da cidade, pois se assim fosse seria exibido na própria colônia. A intenção em vincular um filme, que tem a proposta de mostrar as "mais belas paisagens da Alemanha", teria um propósito maior do que apenas o de conhecimento, por parte da cidade, da pátria de muitos dos habitantes de Venceslau. Poderia nesse caso trabalhar dois objetivos: Nutrir nos alemães distantes da pátria a ideologia nacional-socialista e fazê-la simpática aos habitantes dos lugares que os abrigaram (2009, p. 90).

Soares conclui que "O próprio letreiro, em português e não em alemão ou bilíngue, demonstra que o público alvo da reprodução seria a comunidade não germânica da cidade" (2009, p. 90). Outras fontes apoiam a observação de Soares. Em junho de 1931, 
foi preciso transferir uma exibição em Cosmópolis, no interior de São Paulo, para o cinema local por falta de energia. Somente graças à presença da população brasileira foi possível evitar um prejuízo financeiro naquela noite. $\mathrm{O}$ relato observa:

Embora a história do filme fosse fácil de entender, é notável que os brasileiros tivessem lamentado principalmente que os textos não tivessem sido redigidos em português. E com certeza nós poderíamos contar com sucesso ainda maior, se no futuro levássemos esse pedido em consideração. ${ }^{33}$

Uma exibição em 25 de junho de 1934, em Araçatuba, interior de São Paulo, foi quase exclusivamente para brasileiros. Dos quinhentos espectadores, somente cem eram de origem alemã. ${ }^{34}$ As exibições em Congonhas do Campo e na Casa de Pedra, em Minas Gerais, em 1938, também foram marcadas pelos brasileiros, pois de duzentos espectadores somente entre 10 e 15 eram de origem alemã..$^{35}$ Uma ligação singular entre filmes alemães e brasileiros em uma exibição em março de 1935, em São Caetano, Minas Gerais, mostra que o público brasileiro era levado em consideração pelo menos no planejamento das exibições. Ao lado de filmes como Von Ammergau zum Staffelsee (De Ammergau ao Lago Staffel), Die Ostsee, Teil 5 und 6 (O Mar Báltico, partes 5 e 6) e Sport im Schnee (Esporte na neve) foram exibidos Os 3 cavalheiros e Koko e o cacique. ${ }^{36}$

Não só é notável que na programação havia títulos alemães e brasileiros, mas também que os títulos alemães se referiam ao filme do tipo cultural, enquanto que os outros dois títulos eram desenhos animados. A programação da noite pode ser vista como uma alternativa ao dilema em Cosmópolis, embora não se saiba que língua foi falada naquela noite e se os filmes alemães eram em português. Os desenhos animados não necessitavam de textos explicativos para serem compreendidos. Eles tinham o objetivo de diversão para um vasto público, sem levar em consideração a descendência.

Outro exemplo combina uma recepção ambivalente no lado dos espectadores alemães com um público misto. Em maio de 1934, na Escola Olinda, a exibição começou com um filme de desenho animado Wupp lernt das Gruseln (Wupp aprende a estar com medo) (Hermann Diehl, D 1932), seguido de Mit dem Condorflugzeug von Natal bis Santos (Com o avião Condor de Natal até Santos) e Der schöne Rhein, II Teil (O bonito Reno, parte II). $\mathrm{O}$ filme animado foi pouco adequado para fortalecer uma identidade alemã no Brasil, mas a sua função era, antes de tudo, iniciar um programa divertido para o público. $\mathrm{O}$ subtítulo De Koblenz a Roterdão, em O bonito Reno, conseguiu demonstrar que a exibição das paisagens alemãs foi além das fronteiras nacionais, indo até a Holanda. Da mesma forma, o público alemão podia interpretar o voo em um avião Condor ao longo da costa brasileira como uma obra-prima da tecnologia alemã, que mediu aeronauticamente a nova terra natal. A vista de um avião Condor voando em território brasileiro, cruzando 3 mil quilômetros ao longo da costa brasileira, do Nordeste (Natal) a São Paulo (Santos), em contraste com os 400 quilômetros de Koblenz a Roterdão em $O$ bonito Reno, certamente corroborou para a ideologia nazista "povo sem espaço", Volk ohne Raum. Considerando a posição crítica de muitos teuto-brasileiros 
em relação à ideologia nazista, assim, foi possível chegar à conclusão de que o Brasil e a Alemanha representam diferentes períodos na vida dos teuto-brasileiros: o grande Brasil como a aspiração para uma vida nova e melhor e a pequena Alemanha para a memória ultrapassada. Porém, para o público brasileiro, a programação dos filmes poderia ter tido um diferente efeito: podiam apreciar o filme por sua demonstração de um Brasil de enorme tamanho, em comparação com o pequeno país europeu: a cena de um avião associando Brasil com modernidade e tecnologia em contraste com o ponto de vista do Reno, provavelmente tomada de um barco, um sistema de transporte tradicional e velho.

$\mathrm{Na}$ sua investigação dos cinejornais alemães sobre Brasil exibidos na Alemanha, Thais Blank argumenta que os cinejornais:

[...] ajudaram, [...] a consolidar os vínculos da "comunidade imaginada" nazista. Ao ver representado nas telas do cinema um mundo marcado por traços germânicos, mesmo que este mundo estivesse a milhares de quilômetros de distância, os membros da comunidade podiam se sentir ainda mais fortes, e apoiar o projeto expansionista de seus líderes (BLANK, 2008, p. 11).

Em analogia com a tese de Blank, pode-se argumentar que os filmes culturais da Alemanha projetados no Brasil tiveram uma função similar: produziam om sentimento de pertencer, ser alemão e de fazer parte da comunidade nazista.

Os exemplos, porém, mostram que as exibições da associação, do D.K.D. ou do L.D.L. não deveriam ser vistas como extensão extraterritorial da propaganda cinematográfica alemã ou nacional-socialista, mas como parte da oferta cultural brasileira. Cor- respondências demonstram grande interesse das pequenas cidades em projetar os filmes. Porém, alguns problemas técnicos dificultavam o intuito. Em Friedberg, por exemplo, os filmes dos serviços L.D.L. só puderam ser vistos após quatro anos, pois não havia eletrificação na cidade. A primeira projeção, em 1935, sugere que também foi uma celebração da modernidade, que finalmente chegou à cidadezinha. Para muitos alemães e brasileiros, as exibições foram em geral o primeiro contato com a cinematografia. ${ }^{37}$

$\mathrm{O}$ entendimento que coloca as exibições de filmes exclusivamente em um contexto da propaganda nazista, que atingiu os imigrantes alemães no Brasil, subestima o contexto exibicional e a dinâmica dos programas dos filmes que se dirigiram a um público amplo, incluindo os brasileiros. O trabalho das associações e dos serviços nas regiões brasileiras prova que exibições de filmes culturais do D.K.D. podiam fortalecer o vínculo de uma comunidade imaginada, segundo Benedict Anderson (1991), mas não só o vínculo de uma comunidade imaginada alemã como também o vínculo de uma comunidade brasileira, à qual se sentiam ligados, os imigrantes teuto-brasileiros.

A atividade cinematográfica da Associação de Professores em São Paulo, do D.K.D. ou do L.D.L. não foram as únicas no Brasil nem na América do Sul. Independente dos serviços, a Associação dos Professores Alemães no Rio de Janeiro, por exemplo, organizou uma mostra no Cine Alhambra, Rio de Janeiro. Cerca de setecentas crianças assistiram a filmes como Besuch bei Hindenburg (Visita a Hinderburg), Kinderland-Sonnenland (Terra da criança - terra do sol) (em duas par- 
tes) e Ceylon (Ceilão), um filme cultural da UFA. ${ }^{38}$ A Fundação Faulhaber (Faulhaber Stiftung), em Neu-Württemberg, hoje Panambi, regularmente organizou mostras de filmes de formato normal e operou um cinema itinerante, Wanderkino. ${ }^{39}$ Fora do Brasil, existiam atividades que estabeleciam mostras de filmes pelas escolas. Em 1930, a Associação dos Professores Alemães no Chile informou sobre seus esforços em adquirir filmes culturais gratuitamente. ${ }^{40} \mathrm{~A}$ escola alemã Humboldt, em Buenos Aires, realizou exibições de filmes sonoros em $1934 .{ }^{41}$

\section{Conclusão}

A presente pesquisa realizada no Instituto Martius Staden, em São Paulo, contemplou a análise de correspondências, cartazes e fotos da filmografia exibida no Brasil por intermédio das associações germânicas (ou alemãs), no período que engloba os anos 1930 a 1938, e permitiu obter uma ampla historiografia do cinema brasileiro, partindo-se de uma perspectiva transnacional. A escolha de uma abordagem transnacional possibilitou não só uma nova visão dos filmes antigos, mas acentuou ainda mais que o filme deve ser pensado como tendo sido desde o começo um meio de comunicação internacional. Filmes alemães exibidos no Brasil não eram em si predestinados a um único público e mesmo os filmes que objetivavam a propaganda nazista dos anos 1930 estavam sujeitos às dinâmicas de uma cultura cinematográfica viva.

\section{Agradecimento}

Meus agradecimentos especiais a Silvana Mariani, de Frauenfeld, Suíça, pela leitura e sugestões para o texto, sem as quais eu não poderia ter realizado esta versão em português.

\section{Resumen}

Los discursos sobre el cine nacional normalmente se centran en el lado de la producción y excluyen cuestiones sobre la distribución y la recepción. Desde una perspectiva transnacional, el presente artículo analiza la función de las proyecciones cinematográficas realizadas por asociaciones educativas alemanas en Brasil durante los años treinta. La Asociación de Profesores de Alemán en Sao Paulo, el Servicio Germano-Brasilero de Filmes Culturales y el Servicio de Cine de la Asociación Nacional de Profesores Germano-brasileros, se valieron de las proyecciones cinematográficas para mostrar películas de non ficion (Kulturfilme) de Alemania a los brasileños y a inmigrantes alemanes en Brasil. El artículo sostiene que las proyecciones de dichas películas deben ser interpretadas, no sólo en lo que respecta a la propaganda fascista alemana, sino también en el contexto de una dinámica cultura cinéfila nacional.

Palavras clave: Historiogafia del cine. Recepción. Transnacionalismo. 


\section{Abstract}

Discourses on national cinema normally focus on the production side and exclude questions about distribution and reception. The article analyzes, from a transnational perspective, the role of film screenings of German educational associations in Brazil during the 1930s. The Association of German Teachers in São Paulo, the German-Brazilian Cultural Film Service, and the Film Service of the National Association of German-Brazilian Teachers screened mainly non-fiction films (Kulturfilme) from Germany to German immigrants and Brazilians. The article argues that the reception of the films should be interpreted not only with regard to German fascist propaganda but also in the context of a dynamic national film culture.

Keywords: Film historiography. Reception. Transnationalism.

\section{Notas}

1 Partes desta pesquisa foram publicadas em FUHRMANN, Wolfgang. The Ufa Universe: German cinema in Brazil. In: FINGER, Anke; KATHÖFER, Gabi; LARKOSH, Christopher (Org.). KulturConfusão: on German-Brazilian interculturalities. New York, Berlin: de Gruyter, 2015. p. 179-197 e em FUHRMANN, Wolfgang. Trans-inter-national public spheres. In: BRAUN, Martha et al. (Org.). Beyond the screen: institutions, networks and publics of early cinema. London: John Libbey, 2012. p. 307-314.

2 Deutsche Kulturfilme in Brasilien. Film Kurier, Berlin, v.7, n. 224, 23 Sept. 1925.

3 DIÁRIO G. A. Hoch 1924 - 1926. São Paulo. Arquivo do Instituto Martius-Staden.

4 Deutscher Lehrerverein São Paulo, 4 Aug. 1931. Akten des Landesverbandes deutsch-brasilianischer Lehrer. Mappe 5. Arquivo do Instituto Martius-Staden, São Paulo.
5 Todas as traduções dos títulos são do autor do artigo.

6 O filme Pessoas felizes pode ser identificado como uma produção do diretor e produtor alemão Hubert Schonger. Disponível em: <http://www. filmportal.de/film/frohe-menschen_451f3bc7a8b 9421fb08e9c1060ec090e>. Acesso em: 21 mar. 2016. O filme desportivo também pode ser de Schonger, que vendeu filmes no formato reduzido.

7 Hoje Colégio Visconde de Porto Seguro.

8 Hoje Colégio Benjamin Constant.

9 Só a mostra no Clube Alemão da Ginástica, que obteve renda de $304 \$ 100$ réis, não cumpriu as expectativas da associação. Bericht des Deutschen Lehrervereins - São Paulo ueber die Filmvorführung. G IV f, n. 25/Schubert Chor, Band III, p. 5, 22 maio 1931. Arquivo do Instituto Martius-Staden, São Paulo.

10 MÜLLER, Karl Otto. Kulturfilmdienst in São Paulo. Deutsche Schule São Paulo: Bericht über das Schuljahr 1933 und 1934. São Paulo: Deutsche Schule, p. 76.

11 GÜBELS(?), Richard. 8 Dezember 1935. Correspondência Deutscher Lehrerverein São Paulo 1935/II. Arquivo do Instituto Martius-Staden, São Paulo.

12 DEUTSCHER LEHRERVEREIN, 10 Februar 1933. Correspondência Deutscher Lehrerverein São Paulo 1933. Arquivo do Instituto Martius-Staden, São Paulo.

13 Jahreshauptversammlung des Deutschen Lehrervereins S. Paulo. Lehrerzeitung: Vereinsblatt des Katholischen Lehrervereins in Rio Grande do Sul, Porto Alegre, v. 31, n. 6, p. 6-7, jun. 1932.

14 Atualmente, o Instituto Pré-Teológico é conhecido como Faculdades EST

15 Correspondência Deutscher Lehrerverein São Paulo 1932. 2 jul. 1932. Arquivo do Instituto Martius-Staden, São Paulo. Na sua proposta, Kosche inclui vários títulos que tinha adquirido: um filme de Gerhard Plüschow (1886-1931), que foi um pioneiro alemão da aviação, entre outros locais viajou até a Terra do Fogo em 1929. Os filmes a que Kosche se refere podem ser: Silberkondor über Feuerland (Silberkondor sobre a Terra do Fogo) de 1929; Königin Luise (Rainha Luise), Im Reich der Kohle (No império do carvão) e Vom Gummibaum zum Autoreifen (Da árvore-da-borracha até p pneu), ambos com descrições em português), Priembacke und der Klabautermann (Priembacke e o Kobold do navio), Dornröschen (A bela adormecida), Grotesken im Schnee (Grotescas na eve), Es waren zwei Zirkuskinder (Eram fois meninos de circo), Aufnahmen von Herrn Schulz (Imagens do senhor Schulz), Rio Grandenser Tierwelt (A fauna sul-rio-grandense), 
que mostra como uma cobra devora outra. O filme Arktisfahrt des Grafen Zeppelin (Passeio ártico do conde Zeppelin) foi encomenda de Kosche.

16 Satzungen des Deutschbrasilianischen Kulturfilmdienstes (D.K.D.). GIV G IV f 31/12, Allgemeiner Schriftwechsel 1934-1936, Mappe II. Arquivo do Instituto Martius-Staden, São Paulo.

17 Carta de São Leopoldo. 2 jul. 1932. Correspondência Deutscher Lehrerverein São Paulo 1932. Arquivo do Instituto Martius-Staden, São Paulo.

18 HOLL, Gustav. Bom Jesus. Carte de 14 Jun. 1933. Correspondência Landesverband Deutsch-Brasilianischer Lehrer 1933. Arquivo do Instituto Martius-Staden, São Paulo.

19 Allgemeine Lehrerzeitung, v. 31, n. 5, p. 13, Mai 1934.

20 Landesverband Deutsch-Brasilianischer Lehrer, 46. Rundbrief, Correspondência Landesverband Deutsch-Brasilianischer Lehrer 1935. Arquivo do Instituto Martius-Staden, São Paulo.

21 Idem. Os nomes das cidades estão em partes escritos na grafia antiga.

22 Bericht über die Lehrertagung in St. Maria (Espírito Santo), am 8. und 9. September 1936, Correspondência Landesverband Deutsch-Brasilianischer Lehrer 1936. Arquivo do Instituto Martius-Staden, São Paulo.

23 Landesverband Deutsch-Brasilianischer Lehrer, 46. Rundbrief, Correspondência Landesverband Deutsch-Brasilianischer Lehrer 1935. Arquivo do Instituto Martius-Staden, São Paulo. Ver também Athaides (2007, p. 107).

24 DEUTSCH-BRASILIANISCHER KULTURFILMDIENST. Bericht der Bezirksstelle Sao Paulo über das erste Tätigkeitsjahr. Correspondência Deutscher Lehrerverein São Paulo 1935/I. Instituto Martius-Staden, São Paulo.

25 MÜLLER. Karl Otto. Der Kulturfilmdienst. Deutsche Schule São Paulo: Bericht über das 59. Schuljahr. São Paulo. 1936. p. 88.

26 MÜLLER, KARL OTTO. Kulturfilmdienst in São Paulo. Deutsche Schule São Paulo: Bericht über das Schuljahr 1933 und 1934. São Paulo: Deutsche Schule. p. 75.

27 Schul-und Geschäftsbericht 1936 zur Hauptversammlung vom 10 Januar 21937. GIV f 3110. Arquivo do Instituto Martius-Staden, São Paulo. Não existem números detalhados, mas em 1936 o L.D.L. calculou que precisava de cem filmes em média para manter o serviço. Em 1936, o serviço mantinha 56 filmes, 30 deles antiquados. Deutsche Schule São Paulo: Bericht über das 59. Schuljahr. São Paulo, 1936. p. 88. Ver também Athaides (2007, p. 107).
28 KOSCHE, Walter. São Leopoldo. Carte de 22 abr. 1933. Correspondência Landesverband Deutsch-Brasilianischer Lehrer 1933. Arquivo do Instituto Martius-Staden, São Paulo.

29 Deutschbrasilianischer Kulturfilmdienst (DKD). Tätigkeitsbericht der Bezirksstelle São Paulo des Deutschbrasilianischen Kulturfilmdienstes (August-September 1934). G IV f 31 12, Allgemeiner Schriftwechsel 1934-1936, II. Arquivo do Instituto Martius-Staden, São Paulo.

30 Ver também: COSTA, Jean Henrique. Stuart Hall e o modelo "encoding and decoding": por uma compreensão plural da recepção. Revista Espaço Acadêmico, Maringá, v. 12, n. 136, p. 111-121, set. 2012.

31 Em 1923, de 426 alunos, 259 eram brasileiros de origem alemã, 79 eram alemães e 88 eram brasileiros e de outras nacionalidades. Na comemoração dos 60 anos, em 1938 o número de alunos era 947, dos quais 126 eram alemães, 520 eram brasileiros de origem alemã, 249 eram brasileiros e 52 de outras nacionalidades.

32 Deutsche Zeitung, 29 setembro 1931.

33 DEUTSCHER LEHRERVEREIN SAO PAULO. Bericht des Deutschen Lehrervereins São Paulo über die Filmvorführungen. Carte de 22. maio 1931. G IV f 25 Schubert-Chor. Arquivo do Instituto Martius-Staden, São Paulo.

34 DEUTSCHBRASILIANISCHGER KULTURFILMDIENST. Tätigkeitsbericht der Bezirksstelle São Paulo des Deutschbrasilianischen Kulturfilmdienstes. April/Juni 1934). GIV f 31/12, Allgemeiner Schriftverkehr 1934-1936, II. Arquivo do Instituto Martius-Staden, São Paulo.

35 WLOKA. Bruno. São Paulo. Carte de 22 abr. 1938. Correspondência Landesverband Deutsch-Brasilianischer Lehrer 1937 - 1938. Arquivo do Instituto Martius-Staden, São Paulo.

A falta dos números de espectadores brasileiros não significa que o público era exclusivamente alemão. Parece que os relatórios só mencionavam o número dos alemães quando representaram a minoria no público.

36 MÜLLER, Karl Otto. São Paulo. Carta de 13 mar. 1935. G IV f 31/12, Allgemeiner Schriftwechsel 1934-1936, II. Arquivo do Instituto Martius-Staden, São Paulo.

37 Deutsche Schule São Paulo: Bericht über das 56. Schuljahr. São Paulo 1933 (1934). p. 76.

38 KUNKEL. Rio de Janeiro. Carta de 27 jul. 1933. Akten des Landesverbandes Deutsch-Brasilianischer Lehrer. Mappe 6. Deutscher Lehrerverein Rio de Janeiro und Ruhegehaltskasse.

39 KRAHE, Friedrich. Neu-Württemberg (Panambi). Carte de 22 nov. 1932. Correspondência Landes- 
verbandes Deutsch-Brasilianischer Lehrer 1932. Arquivo do Instituto Martius-Staden, São Paulo.

40 Verein Deutscher Lehre in Chile. 1. Rundschreiben, Ende März 1930. Correspondência Deutscher Lehrer-Verein São Paulo 1930. Arquivo do Instituto Martius-Staden, São Paulo.

41 DEUTSCHBRASILIANISCHER KULTURFILMDIENST. São Paulo. Carta de 5 Sept. 1934. G IV f 31/12, Allgemeiner Schriftwechsel 1934-1936, II. Arquivo do Instituto Martius-Staden, São Paulo.

\section{Referências}

ANDERSON, Benedict. Imagined communities: reflections on the origin and spread of nationalism. London: Verso, 1991.

ATHAIDES, Rafael. Zu Studienzwecken in Paraná: a ação do Círculo Paranaense do Partido Nazista (1933-1942). 2007. Dissertação (Mestre em História) - Programa de Pós-Graduação em História da Universidade Estadual de Maringá, Maringá, 2007. Disponível em: <http:/ / pph.cpanel0032.hospedagemdesites.ws/index.php/show-dissertacoes?task=download \& file $=$ di_linkdocument\&id $=438>$. Acesso em: $1^{\circ}$ maio 2016.

BLANK, Thais. O papel dos cinejornais alemães sobre o Brasil na 'Comunidade Imaginada' Nazista. In: CONGRESSO BRASILEIRO DE CIÊNCIAS DA COMUNICAÇÃO, 31, 2008, Natal. Resumos... Natal, 2008. Disponível em: <http://www.intercom.org.br/papers/ nacionais/2008/resumos/R3-1708-1.pdf $>$. Acesso em: 10 mar. 2016.

CHICKERING, Roger. We men who feel most German. A cultural study of the Pan German League, 1886-1914. Boston: George Allen \& Unwin, 1984.

DIEHL. Hermann. Wupp lernt das Gruseln/ Wupp lernt Gruseln. Produtor: Leo-Film AG (München), 124 metros, 11 minutos, 16mm, preto e branco, sem sonido.
DIETRICH, Ana Maria. Nazismo tropical? O partido nazista no Brasil. 2007. Tese (Doutorado em História Social) - Faculdade de Filosofia, Letras e Ciências Humanas, Universidade de São Paulo, São Paulo, 2007. Disponível em: <http:/ / www.teses.usp.br/teses/disponiveis/8/8138/tde-10072007-113709/>. Acesso em: 21 mar. 2016.

ELEY, Geoff. Nations, publics and political cultures: placing Habermas in the nineteenth century. In: CALHOUN, Craig (Org.). Habermas and the Public Sphere. Cambridge: MIT Press, 1992. p. 289-339.

FRASER, Nancy. Rethinking the public sphere: a contribution to the critique of actually existing democracy. In: CALHOUN, Craig (Org.). Habermas and the public sphere. Cambridge: MIT Press, 1992. p. 109-142.

FUHRMANN, Wolfgang. Imperial projections: screening the Germany colonies. Oxford: Berghahn Books, 2015.

GERTZ, Réne. Influência política alemã no Brasil na década de 1930. Estudios Interdisciplinarios de América Latina y el Caribe, Tel Aviv, v. 7, n. 1, 1996. Disponível em: <http:// www7.tau.ac.il/ojs/index.php/eial/article/ view/1186/1214>. Acesso em: 21 mar. 2016.

HALL, Stuart. Encoding, decoding. In: DURING, Simon (Org.). The cultural studies reader. 2. ed. London: Routledge, 1999. p. 507-517.

HIGSON, Andrew. The limiting imagination of national cinema. In: HJORT, Mette; MACKENZIE, Scott (Org.). Cinema and nation. London; New York: Routledge, 2000. p. 63-74.

The concept of national cinema. Screem, Glasgow, v. 30, n. 4, p. 36-46, autumn 1989.

JARVIE, Ian. National cinema: a theoretical assessment. In: HJORT, Mette; MACKENZIE, Scott (Org.). Cinema and nation. London; New York: Routledge, 2000. p. 75-87. 
LUTHER, Tammo. Volkstumspolitik des Deutschen Reiches 1933-1938: Die Auslanddeutschen im Spannungsfeld zwischen Traditionalisten und Nationalsozialisten. Wiesbaden: Franz Steiner, 2004.

MÜLLER, Jürgen. Nationalsozialismus in Lateinamerika: Die Auslandsorganisation der NSDAP in Argentinien, Brasilien, Chile und Mexiko, 1931-1945. Stuttgart: Hans-Dieter Heinz, 2000.

MÜLLER, Karlö Otto. Der Kulturfilmdienst. Deutsche Schule São Paulo: Bericht über das 59. Schuljahr. São Paulo. 1936. p. 87-91.

MÜLLER, Karl Otto. Kulturfilmdienst in São Paulo. Deutsche Schule São Paulo: Bericht über das Schuljahr 1933 und 1934. São Paulo: Deutsche Schule. p. 74-76

NAZARIO, Luiz. Nazi film politics in Brazil, 1933-1942. In: VAN DE WINKEL, Roel; WELCH, David (Org.). Cinema and the Swastika: the international expansion of the Third Reich. New York: Palgrave MacMillan, 2007. p. 85-98.

NIPPERDEY, Thomas. Verein als soziale Struktur in Deutschland im späten 18. und frühen 19. Jahrhundert. Eine Fallstudie zur Modernisierung. In: NIPPERDEY, Thomas (Org.). Gesellschaft, Kultur, Theorie: Gesammelte Aufsätze zur neueren Geschichte. Göttingen: Vandenhoeck \& Ruprecht, 1976. p. 175-205.

PRINZHORN, [nome desconhecido]. Kulturfilmpropaganda. Die Deutsche Schule im Auslande, Wolfenbüttel: Heckner, v. 22, n. 12, p. 405, Dez. 1930.

SCHMIDT, Franz. Kulturpropaganda und deutsche Auslandschulen. Die Deutsche Schule im Auslande, Wolfenbüttel, v. 21, n. 1, p. 1-10, März 1930, p. 1-10.

SOARES, Bruno Pinto. Germanismo e nazismo na colônia alemã de Presidente Venceslau (1923-1945). 2009. Dissertação (Mestrado em História) - Faculdade de Ciências e Letras de Assis, Universidade Estadual Paulista, São Paulo, 2009.
VON SIMSON, Olga Rodrigues Morais. Imagem e memória. In: SAMAIN, Etienne (Org.). O fotográfico. 2. ed. São Paulo: Hucitec, 2005. p. 19-32. 